\title{
Entrevista Com Ruth Rosengarten. “Atualmente A FOTOGRAFIA FEMINISTA É DIVERSA E BASTANTE ELÁSTICA, AO INVÉS DE SE FIXAR NOS VELHOS BINARISMOS"
}

\author{
Maria da Luz Correia \& Carla Cerqueira
}

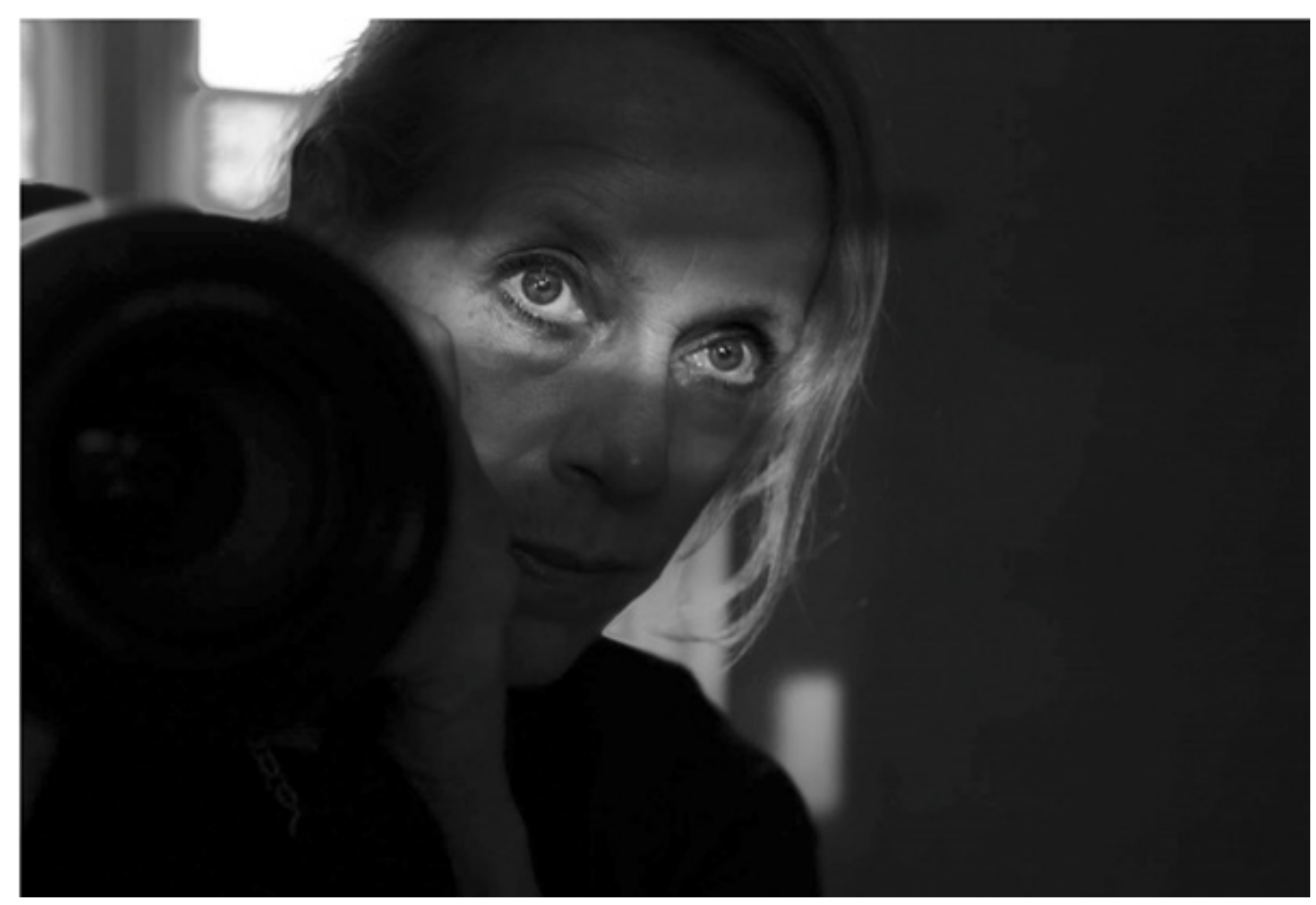

Figura 1: Self, Ruth Rosengarten, 2013

Fonte: http://ruthrosengarten.com/

Tudo começou com o texto "Pontos de vista: Fotografia e Feminismo no contexto do Pós-modernismo" que encontrámos casualmente num já antigo número da Revista Comunicação e Linguagens, datado de 1988. Ruth Rosengarten era a autora desse ensaio e conhecíamos já o seu trabalho Contrariar, Esmagar, Amar A Família e o Estado Novo na obra de Paula Rego, editado pela Assírio \& Alvim, em 2009. A investigadora, artista e curadora, doutorada em História de Arte pelo Courtauld Institute of Art da Universidade de Londres, nasceu em Israel, viveu em Joanesburgo, Londres e Lisboa, e radicou-se mais recentemente numa pequena aldeia em Cambridgeshire, no Reino Unido. Foi entre Cambridgeshire e Braga que, há uns meses, duas décadas passadas sobre o seu pioneiro ensaio em torno da prática fotográfica e da teoria feminista, falámos com Ruth Rosengarten por videoconferência, pondo-lhe várias questões, em torno do cruzamento entre a fotografia e o género'.

\footnotetext{
' Note-se que as perguntas e respostas que aqui se reproduzem, embora resultem em grande medida desta conversa, foram depois trocadas por escrito com a entrevistada e ainda por nós posteriormente editadas e traduzidas para o português.
} 
Maria da Luz Correia \& Carla Cerqueira - Um dos seus primeiros ensaios é sobre fotografia e feminismo. Para ser mais precisa, sobre o papel da teoria feminista e da prática fotográfica na crítica da autoridade hegemónica e na detração da representação. O que mudou desde então? O que significa trabalhar através de uma lente feminista?

Ruth Rosengarten - Esse ensaio foi escrito na década de 1980 - Eu era muito jovem, e estes eram realmente os primórdios das conversas sobre pós-modernismo e representação, bem como feminismo e representação, hibridez e multiculturalismo em relação às artes. Eu acho que há uma necessidade tão urgente do feminismo hoje como havia nessa altura, mas talvez se tenha deslocado para outras áreas, para diferentes contextos. Atualmente, quando eu olho para esse ensaio posso ver de onde eu venho, mas espero que a minha escrita hoje sobre esse assunto possa ser um pouco mais matizada, menos programática ou didática. Mas no momento em que escrevi esse ensaio, o pensamento de Judith Butler sobre a performatividade do género - e toda a questão da fluidez do género - apenas espreitava no horizonte. Atualmente, a performatividade é um ingrediente importante na discussão sobre género e na relação do género com as artes visuais. Também acho que, no momento desse ensaio não fiz uma distinção clara entre diferentes tipos de feminismo - isso ficou muito mais claro para mim na década de 1990 e foi consolidado nos meus trabalhos sobre Paula Rego. O feminismo da diferença (o modelo psicanalítico) e o feminismo da igualdade (o modelo marxista / economicista) nem sempre se apoiam ou são conciliáveis. Há também questões sobre a diferença cultural e de classe que são muito mais urgentes hoje. Qual é o papel da pornografia? A moda é libertadora ou escravizadora? Estou preocupada com a igualdade de oportunidades, de remuneração, de visibilidade. Penso que o feminismo como uma prática libertadora que estendeu um discurso favorável a outras esferas culturais e que continua a fazê-lo.

M. L. C. \& C. C. - Nesse ensaio, a Ruth comenta sobre diferentes trabalhos fotográficos feministas, como os de Sherrie Levine, Barbara Kruger, Sally Mann, Jo Spence, Holger Trülsch \& Vera Lehndorff, Cindy Sherman... Quais os projetos fotográficos feministas que escolheria atualmente se escrevesse sobre fotografia e feminismo?

R. R. - Ah, essa é uma ótima pergunta, com uma resposta muito longa. De qualquer forma, olhando para esse ensaio hoje, percebo o quão centrada eu estava no trabalho dentro de uma hegemonia cultural: quase todas as artistas que discuti eram americanas ou britânicas. As obras de Sherrie Levine e Barbara Kruger não são tão interessantes para mim hoje, mas também há importantes figuras históricas dignas de menção. Alguém como Mary Kelley continuou a ser historicamente interessante, assim como o continuaram a ser Cindy Sherman, Jo Spence e Sally Mann, de maneiras muito diferentes. O trabalho de Claude Cahun tornou-se central e permanece extremamente importante - um exemplo muito antigo da problemática do género e da sua relação com a máscara e a performatividade. Definitivamente incluiria mais trabalho performativo - por exemplo, embora a fotografia fosse apenas um documentário sobre o trabalho de desempenho de Ana Mendieta, acho que ela é uma figura-chave. Oh, e muito mais trabalhos vindos de 
todo o mundo. Da Índia, Pushpamala N. que, como Sherman, se colocou em imagens encenadas. Do Japão, Yasumasa Morimura, que é um homem e cuja inclusão, portanto, seria uma problemática interessante do género e do feminismo. A artista marroquina Latifa Echakhch ensaia identidades de género num contexto em que a diferença rapaz / rapariga produz expectativas bastante divergentes de experiência de vida. Num contexto completamente diferente, e de uma maneira muito mais silenciosa, a artista fotográfica finlandesa Elina Brotherus trabalha com as expectativas geradas pela feminilidade. Depois, há artistas fotográficas que trabalham com a ideia de fluidez de género, como Catherine Opie, Melody Melamed, Loretta Lux, Zakary Drucker e Rhys Ernst. Yishay Garbasz, uma artista israelita transgénero/crossover, que trabalha em fotografia e performance. Zoe Leonard também explora questões de feminilidade e raça, tal como Carrie Mae Weems e Lorna Simspon, a fotógrafa cubana Maria Magdalena Campos Pons, e a artista queniana Ingrid Mwangi. Descrevendo-se como uma ativista visual, a sul africana Zanele Muholi fez uma marca muito significativa com as suas poderosas imagens fotográficas explorando raça, identidade de género e preferências sexuais, Oh, há tantas outras/os artistas interessantes, trabalhando em todos os meios e práticas de fotografia.

M. L. C. \& C. C. - Existe um olhar feminino na forma de fazer e pensar a fotografia? Algo que possa descrever uma estética feminista?

R. R. - Não estou muito certa quanto a isso. Eu responderia não à pergunta "se há um olhar feminino" - embora se há algo como o feminismo, que existe, eu diria que deve haver uma estética feminista. Eu penso que, como em outras áreas de expressão e de esforço, atualmente a fotografia feminista é diversa e bastante elástica, ao invés de se fixar nos velhos binarismos. Androginia, por exemplo, é uma das caraterísticas da prática fotográfica feminista - e quero dizer androginia não só de uma maneira que descreve género ou sexualidade, mas também como princípio de fluidez e ambiguidade.

M. L. C. \& C. C. - Como definiria o feminismo atualmente?

R. R. - Para mim, atualmente o feminismo continua a ser essencial e isto em duas vertentes: a igualdade e a diferença. E, por diferença, quero dizer não apenas as diferenças de género e a possibilidade de superar essas diferenças através de sínteses fluídas variadas, mas também diferenças entre as mulheres. Penso que somos muito mais cautelosas hoje do que, digamos, nos anos 80 , de modo a não cair numa armadilha essencialista $e$ a reconhecer a diferença cultural. Então, o feminismo significa coisas diferentes em diferentes contextos. Ainda há países em que as mulheres têm que ganhar tantas liberdades pessoais e políticas, coisas que agora damos por garantidas, por exemplo, em Inglaterra, onde eu moro, mesmo se ainda temos de lutar contra opressões. Artistas de todo o mundo têm sido dinâmicas e inovadoras na forma como aproveitaram diferentes - e frequentemente críticas - formas de cultura visual ao expressar essas diferentes prioridades.

M. L. C. \& C. C. - Ao ler sua biografia, fica-se com essa impressão de um certo nomadismo. A Ruth escreveu em algum lugar que nunca decidiu o que queria, "entre fazer 
coisas e escrever sobre pessoas que fazem coisas". O seu trabalho divide-se entre duas instituições, dois mundos diferentes: a arte e a academia. Também se mudou com frequência, tendo já vivido em diferentes países: Israel, África do Sul, Portugal, Inglaterra, teve uma longa estadia na Austrália na década de 1990. Este nomadismo profissional e geográfico tem certamente prós e contras...

R. R. - Bem, eu acho que os contras são talvez mais óbvios, ou melhor, num contexto em que as pessoas falam muito sobre identidade, identificação e pertença, mover-se parece estar suspenso, não envolvido, desligado, desenraizado. Parece assim e, de certa forma, é assim. Mas para mim isso não é uma coisa negativa. Muito pelo contrário. Sinto-me em casa em vários lugares diferentes e, ao mesmo tempo, sinto-me ligeiramente separada desses lugares, uma espécie de não pertença em certo sentido que não me é desconfortável. Ao contrário da estabilidade das raízes, tive a sorte de ter acesso a diferentes contextos, diferentes idiomas, diferentes geografias e grupos de pessoas, todas/os e as/os quais são extremamente importantes para mim.

M. L. C. \& C. C. - Relacionadas com a sua abordagem artística e teórica, as ideias de arquivo e de memória parecem muito importantes para si: há três anos, por exemplo, a Ruth foi a curadora da exposição Entre Memória e Arquivo no Museu Berardo, em Lisboa...

R. R. - Eu suponho que haja algo como um Zeitgeist: nas últimas duas décadas, a questão do arquivo tornou-se central, em termos gerais e na prática artística, em particular. Como muitos artistas e académicos de hoje, estou interessada na ideia de memória, tanto pessoal quanto coletiva e também na relação entre memoralização e arquivo. $O$ nexo documento-monumento invoca a ideia do arquivo, ou depende dele, e a exposição que se referiram, abordou essa questão a partir das obras escolhidas daquela coleção particular. Do arquivo da família ao arquivo público - existem diferentes tipos de arquivos -, mas, em geral, suponho que eu esteja interessada nas redes que usamos para ordenar e tabular o conhecimento e a informação, e a partir do qual recuperamos aspetos do passado. Eu sempre fui fascinada pelos sistemas de ordenação - as taxonomias, mas não só - e sempre obcecada com as formas de ordenar os meus próprios papéis, os fragmentos, as notas de leitura, os documentos pessoais, as fotografias, as notas do diário: todos requerem sistemas para torná-los acessíveis no futuro. A grelha - que é outra maneira de dizer o sistema de arquivo - e o que ela contém, bem como o que ele deixa escapar através das brechas das categorias, fascinou-me desde que me lembro. Mas também estou realmente interessada na diferença entre a história - o que implica uma certa narrativa e um relato - e o arquivo, que é apenas uma das fontes a partir das quais a história se desenha.

M. L. C. \& C. C. - Definir-se-ia a si própria como uma arquivista?

R. R. - Eu suponho que, como todos os bons arquivistas, eu poderia definir-me como uma arquivista falhada: está-se sempre dois passos atrás (ou mais) em relação ao sistema perfeito! O meu fascínio pelo arquivo também significa que eu desperdicei demasiadas horas tentando conceber sistemas perfeitos para o armazenamento e a 
recuperação de informações: esse é o histórico pessoal do meu interesse em arquivos.

M. L. C. \& C. C. - Voltando ao seu ensaio da década de 1980 sobre fotografia e feminismo, a Ruth reportava-se aí ao marco histórico do advento da fotografia. Como vê hoje o advento do digital?

R. R. - A digitalização muda tudo. A produção e a manipulação de imagens digitais deslocaram radicalmente as práticas e as teorias passadas da fotografia e remodelaram os seus parâmetros. O advento da era digital e a proliferação de plataformas de partilha de fotos on-line que este gerou, desencadeou ainda um volume sem precedentes de fotografias com circulação pública, no qual as distinções entre fotografias amadoras, vernaculares, documentais e artísticas são muitas vezes pouco apagadas. Certamente, este apagamento em si não é novo, mas enfatiza o facto de que a "fotografia" sempre foi assim: um termo de guarda-chuva para uma variedade de atividades. Contudo, com o digital, os usos da fotografia são usos inteiramente novos da imagem, que - essencialmente imaterial - pode agora ser transferida para qualquer suporte. Isto sugere que, como argumenta Fred Ritchin, "para aqueles que pensam os média digitais como apenas fornecendo instrumentos mais eficazes, o que estão a testemunhar atualmente é uma evolução nos média."

M. L. C. \& C. C. - Nesse ensaio reportava-se à forma como a especificidade da fotografia era definida pela sua contiguidade com o real, pela sua indicialidade. A emergência do digital parece também introduzir uma rutura neste quadro do pensamento indicial...

R. R. - A "fotografia" digital afrouxa essa ligação firme entre "a fotografia" e o vestígio indicial. A captura de imagens digitais, ao mesmo tempo que simula fotografia em alguns aspetos, oferece uma gama de capacidades técnicas que alteram essa relação particular do artefacto com o vestígio indicial e a ligação de evidência assim forjada com o tempo passado. Por outras palavras, a digitalização mudou o estatuto ontológico da "fotografia". A substituição do suave grão pelo mosaico de pixéis é sintomática do facto de que, estritamente falando, as imagens digitais não são de modo algum fotográficas, uma vez que os significantes codificados são dados abstratos que podem ser facilmente tratados como abstrações, sem qualquer conexão com o real. Na câmara escura digital a inventividade contrapõe-se à indicialidade. Enquanto que a ideia de que a fotografia era indicial servia como garante do efeito de verdade que a distinguia de outras formas de representação, a elaboração digital põe à vista do espetador a natureza construída da imagem. Isto é realmente interessante. E muitas/os artistas - incluindo fotógrafas feministas, embora não exclusivamente - usam isso para efeitos extremamente dinâmicos e diversos.

M. L. C. \& C. C. - Permite-nos então o digital abandonar o mito da verdade fotográfica?

R. R. - É importante enfatizar que continuidades culturais significativas unem as novas imagens digitais às velhas fotografias analógicas e aos hábitos de visualização que estas fomentaram, suscitando certas expectativas por parte de quem visiona, por exemplo, 
a assunção persistente do "efeito de verdade" do trabalho fotográfico, do seu relacionamento privilegiado com o real. Isto persiste, por exemplo, na forma como as imagens fotográficas são usadas hoje nos média sociais como prova ou evidência. Apesar do facto de que, mais do que as suas homólogas analógicas, as imagens digitais podem ser alteradas e "reparadas" facilmente e até mesmo radicalmente, a noção de que uma fotografia é uma relíquia do tempo continua, em certos domínios, a ser penetrante.

Traduzido por Carla Cerqueira e Maria da Luz Correia

\section{NotAs BiográficAs}

Maria da Luz Correia é Professora Auxiliar no Departamento de Línguas, Literaturas e Culturas na Universidade dos Açores e investigadora do Centro de Estudos de Comunicação e Sociedade da Universidade do Minho. É doutorada em Ciências da Comunicação, pela Universidade do Minho e em Sociologia, pela Université Paris Descartes - Sorbonne. Tem publicado nas áreas da cultura visual, da teoria da imagem e da fotografia.

E-mail: maria.If.correia@uac.pt

Universidade dos Açores, Faculdade de Ciêncais Sociais e Humanas, Ladeira da Mãe de Deus, 9501-855 Ponta Delgada, Portugal

Carla Cerqueira é doutorada em Ciências da Comunicação (especialização em Psicologia da Comunicação). Bolseira de pós-doutoramento em Ciências da Comunicação (SFRH/BPD/86198/2012) do Centro de Estudos de Comunicação e Sociedade (CECS), Universidade do Minho, Portugal e investigadora visitante do Departamento de Media, Comunicação e Cultura, da Universidade Autónoma de Barcelona, Espanha, e do Departamento de Ciências Sociais, da Universidade Erasmus de Roterdão, Holanda. É também Professora Auxiliar da Universidade Lusófona do Porto. Autora de vários livros, capítulos e artigos em revistas científicas, os seus interesses de investigação incluem género, feminismos, ONGs e estudos de média.

E-mail: carlaprec3@gmail.com

Centro de Estudos de Comunicação e Sociedade, Universidade do Minho, Campus de Gualtar, 4710-057 Braga, Portugal

* Submetido: 07-11-2017

*Aceite: 19-11-2017 